\title{
PROBLEMAS SUCESORIOS DE ENRIQUE IV DE CASTILLA
}

\author{
Pedro Floriano Llorente \\ Universidad de Oviedo
}

\section{ANTECEDENTES HISTORICOS}

El hecho histórico es sobradamente conocido. Consta en todas las crónicas contemporáneas, ha sido comentado por los historiadores de todos los tiempos, se lanzó a la voracidad popular en desvergonzadas coplas y hasta se le ha estudiado clínicamente. No pretende, pues, la exposición que sigue ninguna novedad, sino simplemente situar el documento objeto del presente estudio en el lugar histórico que le corresponde.

Enrique IV de Castilla, casado con Dña. Blanca, hija primogénita del rey Juan II de Navarra, hubo de separarse de ésta a los doce años de convivencia, dándose por nulo este matrimonio, en realidad no consumado. La sentencia de nulidad fue confirmada en Roma en 1453.

Aún era príncipe Enrique IV; pero pocos meses después de la disolución canónica del vínculo, en julio de 1454, llegó a ser rey por muerte de su padre Juan II de Castilla y de León y, no obstante el fracaso de la unión anterior, deseando alcanzar sucesión, el nuevo rey contrajo segundo matrimonio con Dña. Juana, infanta de Portugal, hija del rey D. Duarte y hermana de Alfonso $V$ el Africano.

El drama conyugal se repitió. Los reyes vivieron juntos cerca de siete años sin señales, al menos sensibles, de intimidad; lo que no era obstáculo para que, tanto el uno como el otro cónyuge, las dieran harto evidentes de sus excursiones al extrarradio matrimonial. 
En tan anómalas circunstancias, en 1461 la reina quedó encinta, dando a la luz el 28 de febrero del año siguiente una niña a la que se puso por nombre Juana.

Este hecho produjo dos reacciones muy distintas, si no contrarias. En la corte estalló el regocijo. Se bautizó a la niña siendo padrinos el conde de Armagnac, embajador de Francia, y el marqués de Villena, y Madrinas la infanta Dña. Isabel (la futura reina Católica) y la marquesa de Villena. Se decretaron fiestas y alegrías por todo el reino, y el rey convocó cortes para que fuera jurada la nueva Princesa de Asturias, Io que se realizó en solemne ceremonia en Toledo el día 9 de mayo. El Arzobispo de Toledo tuvo en sus brazos a la tierna infanta, que contaba poco más de dos meses, mientras le prestaban reverencia y acatamiento besándola la mano, los infantes D. Alfonso y Dña. Isabel, la nobleza y todos los dignatarios de la Iglesia.

Otra reacción muy diferente se produjo ante el acontecimiento. Esta se originó también en los elevados estratos de aquella sociedad; pero no tardó en prender en las clases populares. Se recordó el fallido matrimonio del rey con Dña. Blanca de Navarra, anulado por impotencia recíproca de ambos esposos, canónicamente reconocida; echóse de ver la tardía fecundidad de la reina Juana, coincidente con los rumores que venían corriendo sobre los devaneos de ésta con un caballero de la corte, favorito del rey, D. Beltrán de la Cueva, por lo que la lógica torpe de la malevolencia atribuyó a $D$. Beltrán la paternidad de la niña que quedó marcada con el infamante apodo de "La Beltraneja", estigmatizando así desde la cuna a esta desgraciada criatura, que sin la menor culpa por su parte fue víctima del desbarajuste político y de la anarquía que ya venía destrozando a Castilla desde el advenimiento de los trastámara. De ella se hizo pretexto para partidismos y banderías, siendo juguete de las rebeldías y ambiciones, piedra de escándalo para todo el reino y aún hasta objeto de desprecio para su propio padre.

Todo lo soportó con una actitud ejemplar; primero con la pasividad propia de la infantil inconsciencia, y luego, al alcanzar el sentido de la madurez, con una irreprochable dignidad y una vida entregada de lleno al ejercicio de todas las virtudes, por lo que mereció ser designada, allá en Portugal donde acabaron sus días, con otro sobrenombre que anulaba por completo al anterior: "La Excelente Señora".

Enrique IV, acosado por los nobles, no tuvo inconveniente en reconocer su propia deshonra, haciendo jurar como Príncipe heredero de Castilla a su hermano Alfonso (1465), en perjuicio de Dña. Juana a la que oficialmente había reconocido como hija. Mas no bastó con esto a los revoltosos; el rencor y el desprecio contra el rey, la envidia desper- 
tada por el favorito D. Beltrán a quien Don Enrique había compensado de la pérdida del Maestrazgo de Santiago con el ducado de Alburquerque, la posesión de numerosas villas en Castilla y de copiosas riquezas en Ubeda y Baena, llevó a los conjurados a intentar la deposición del soberano, y montaron la infamante y soez "farsa de Avila" en la que en efigie lo despojaron de las insignias reales, deshaciendo después, poco menos que a coces el monigote que lo representaba al tiempo que se le decía "abajo puto".

Enseguida proclamaron por rey al infante D. Alfonso quien ostentó tal título durante tres años; y, dígase lo que se quiera reinó en efecto, pues le acataba y obedecía una facción casi tan numerosa como la que se conservó leal al rey legítimo, facción que con diversas alternativas iba engrosando sus filas día por dia, y que hubiera terminado por consolidarse en el poder, a no haberse interpuesto la muerte que, en una forma que todavía no ha sido aclarada, se llevó consigo al pretendiente que murió en Cardeñosa el 5 de julio de 1468.

Este fatal acontecimiento concretó la cuestión en la rivalidad existente entre el marqués de Villena y $\mathrm{D}$. Beltrán de la Cueva. Para la corona no había heredero varón y solamente podrían aspirar a ella la Infanta Dña. Isabel, hija de D. Juan II y de su segunda esposa Isabel de Portugal ( $y$, por consiguiente, medio hermana de Enrique IV, que era hijo de Juan Il y de su primera esposa María de Aragón) y la Princesa Juana, la cual, como hemos dicho, eran muchos los que no creian que fuese hija del rey.

El Marqués de Villena influyó mucho para que el rey aceptase este deshonroso supuesto, prometiéndole conseguir la paz para Castilla y la sumisión de los sublevados, para lo cual habría de reconocer a doña Isabel como heredera del trono; y aceptada por Enrique esta solución que reiteraba su deshonra, en el lugar de los Toros de Guisando, el 19 de septiembre de 1468 , se firmó un pacto entre él y su hermana, por el que ésta quedó reconocida como Princesa y sucesora en los reinos, el rey prometió convocar cortes para que como tal fuera jurada y se comprometió a no casar a Isabel contra su voluntad, aunque ésta, para contraer matrimonio, tenía que contar con la aquiescencia de su hermano. Este quedaba divorciado de su mujer, la cual fue inmediatamente separada de su hija.

Con este tratado, al parecer se había encontrado una fórmula de paz entre los bandos y aclarado al mismo tiempo el problema sucesorio. Pero la verdadera paz dependía de las determinaciones que tomara Isabel respecto a su matrimonio. Surgieron varios pretendientes que sucesivamente fueron rechazados. Tenía el rey su candidato; este era el Príncipe Carlos, hermano del rey de Francia Luis XI, muchacho enfer- 
mizo, cacoquimio y deforme, del cual la Princesa no quería ni aun siquiera oír hablar; y no sólo por las condiciones físicas del pretendiente, sino porque ella ya tenía hecha su elección, que era, no solamente la que menos agradaba al rey sino que además era la que menos convenía al rey Luis de Francia. El elegido por Isabel fue, como de todos es sabido, D. Fernando, Infante de Aragón, hijo de Juan II y de Juana Enríquez, del cual, aparte toda consideración de conveniencias políticas se sentía la princesa sinceramente enamorada. El rey y Villena se oponían a esta unión, pero los dos príncipes, tras muchas incidencias que no son del caso pormenorizar ahora, salvando toda clase de obstáculos, alguno de los cuales no fue canónicamente hablando muy correcto, contrajeron matrimonio en Valladolid, el 18 de octubre de 1469 en casa de Juan de Vivero.

La reacción de $D$. Enrique fue inmediata. Dio cuenta del acontecimiento al rey francés, al que en manera alguna convenía la unión de Castilla y Aragón y Luis XI envió enseguida una embajada extraordinaria presidida por el Cardenal de Albi y en la que figuraba el mismo rechazado Príncipe Carlos; y como esta embajada no podía ya impedir el matrimonio rato y ya consumado (esto último hasta con solemnidad jurídica) de Fernando e Isabel, se pretendió el de Carlos con Dña. Juana la llamada Beltraneja, que a la sazón solamente contaba siete años, haciendo revertir en ésta los derechos sucesorios adquiridos por Isabel en virtud del tratado de los Toros de Guisando, que era, por consiguiente, indispensable invalidar.

Una indignidad más nada importaba y ésta se consumó en un documento extendido en el lugar de Valdelozoya de Santiago el día 26 de octubre de 1470 , siendo el estudio de este documento el objeto del presente trabajo.

\section{EL DOCUMENTO}

También es conocida esta pieza diplomática, y quizá su análisis y estudio no satisfaga a los que profesan el fetichismo de lo inédito; mas hemos de decir para su satisfacción y para justificación nuestra, si ello fuera necesario, que se trata de un original, íntegro y auténtico y que lo que del mismo está publicado proviene de copias tardias que contienen lagunas o variantes en su redacción y que además, son incompletas.

Nuestro original está extendido sobre tres pliegos de papel de tamaño folio, de filigrana de "la mano", midiendo la totalidad del pliego 307 por $222 \mathrm{~mm}$., con amplios márgenes que reducen a 225 por 118 la caja de la escritura. De estos tres pliegos, dos, que son los que contie- 
nen el documento, están incluidos uno en el otro y cosidos al medio por su doblez. El tercero permaneció en blanco, cosido por puntadas a los estambres de los anteriores.

En el cuadernillo asi formado conviene, pues, considerar las partes siguientes:

1. $^{\text {a }}$ La escritura por la cual Enrique IV y su esposa la reina Juana reconocen por su hija legítima a la Princesa Juana y la declaran heredera de sus reinos de Castilla y de León, anulando la declaración hecha a favor de Dña. Isabel como tal princesa heredera.

2. Escritura por la que los nobles y dignatarios del reino, en el mismo acto, confirman la escritura anterior, anulan el juramento hecho a favor de doña Isabel a raíz del acuerdo de los Toros de Guisando, y reiteran el que hicieron a favor de doña Juana la Beltraneja en el año 1462.

3. ${ }^{a}$ Validación mediante subscripción notarial de los dos documentos anteriores.

4. ${ }^{a}$ Tres folios en blanco, que son el 4, 5 y 6 . Es de advertir que en el verso del folio 5 aparece una nota escueta escrita con letra del final del siglo XV, en la que se lee: del Rey Don Enrique; y que en el verso del folio 6 se extiende la siguiente nota de catalogación: Dec/aración de los' $S^{\text {res }}$. Reyes don Enrique y doña Juana, de como la princesa doña Juana es su hija y sucesora en los Reynos; y el juramento que por ello ycieron el Marqués de Santillana y otros.

La primera de las escrituras contenida en esta unidad diplomática es aquella por la que Enrique IV y su esposa Juana de Portugal, reconocen a la Princesa Juana como hija legítima y heredera de sus reinos.

Diplomáticamente puede ser considerado este documento como epístola de carácter pragmático con dirección de tipo universal, a la manera de las antiguas "cartas abiertas" y que persistió hasta las más recientes "cartas de privilegio" (Conoçida cosa sea a todos...). La intitulación es de persona conjunta, pues la integran la del Rey con su protocolo completo, según la formulación intitulativa de todos los documentos reales a partir de los comienzos del siglo XIV, y la de la Reina simplemente como muger del dicho Rey mi sennor.

El preámbulo-motivación es una exposición detallada de las circunstancias históricas que arriba quedan reseñadas; claro es que expuestas en la forma que más convenía a los intereses y, sobre todo, a los objetivos más inmediatos de los soberanos.

El Rey afirma que por el derecho sucesorio la herencia de la Corona correspondía a su hija doña Juana, y como tal fue jurada y reconocida por todos los estamentos del reino. Este juramente primero se anuló por un tratado posterior (el de los Toros de Guisando) en el que se 
prescindió del derecho de doña Juana, jurando, intitulando y proclamando como princesa heredera de Castilla a la Infanta doña Isabel; pero este segundo juramento, confiesa el Rey que se hizo para atajar algunas guerras e males e divisiones que a la sazón ocurrían en Castilla, y bajo la promesa de la Infanta, formulada asimismo bajo juramento, de apartarse de las parcialidades y banderías, someterse a la autoridad de su hermano, no recibir mercedes sino de él y, sobre todo, no casarse sino con aquella persona que él designara. Nada se dice del acuerdo recíproco igualmente estipulado y jurado por el monarca, esto es, de que éste no obligaría a Isabel a contraer matrimonio contra su voluntad, y que ésta no podría casarse sin consentimiento del Rey.

Este sigue en nuestro documento desarrollando su exposición a la medida de sus conveniencias: Isabel, nos dice, no ha cumplido nada de lo convenido, pactado y jurado; antes por el contrario, ha quebrantado su fe, yendo contra ello y contra las leyes del Reino, y cometiendo actos de menosprecio para el soberano y desconociendo de muchas maneras su autoridad. Naturalmente, no concreta hecho alguno; pero bien se infiere que alude al matrimonio de la Infanta con D. Fernando, Príncipe de Aragón, diciendo que todo ello había producido gran turbación y escándalo; pero ocultando, claro es, sus tratos con el Rey de Francia para casar a Isabel con el enfermizo Príncipe Carlos, que ya de antemano habia sido rotunda y definitivamente rechazado por la Infanta.

En vista de todo esto, y como una consecuencia en la que no resplandece ciertamente la lógica, nos dice el Rey que cae en la cuenta de que el juramento hecho a Isabel fue en daño y perjuicio de la Princesa Juana, de su derecho y contra el juramento primero, por lo que este juramento segundo no vale, y no debe ser guardado ni cumplido.

Tras este preámbulo, en el que nada se dice y todo se adivina, entra el documento en una parte dispositiva en la que el rey revoca solemnemente el juramento hecho a Isabel, lo da por ninguno y sin ningún valor ni efecto $y$ ordena que no se guarde ni cumpla por cuantos lo otorgaron: grandes, caballeros, prelados y procuradores de las villas y ciudades. Pero a los fines políticos que se perseguian, se necesitaba algo más. Era preciso legitimar a la Princesa doña Juana, que de una manera más o menos explícita había sido declarada ilegítima en el tratado de los Toros de Guisando. Estaba presente al otorgamiento del documento que ahora comentamos la misión diplomática francesa que presidia el Cardenal de Albi, y aun el mismo Príncipe Don Carlos, Duque de Guiena y hermano del Rey Luis XI; misión que venía, precisamente, para atemperar las consecuencias del matrimonio de Fernando e Isabel. Una unión de Aragón y Castilla, a las puertas de Francia, podía atenuar su peligrosidad, mediante una alianza sobre bases inconmovi- 
bles entre Castilla y Francia; y ya partiese la idea de Enrique IV o bien de Luis XI, la mejor manera de sellar esta alianza era mediante el matrimonio de la Princesa Juana con el Duque de Guiena, que a la larga (pues Juana contaba a la sazón tan solamente siete años) colocaría sobre las sienes del francés la corona de Castilla. Condición previa e insoslayable para esto era la de reivindicar el honor de Juana, disipar, a lo menos oficialmente, las sombras que se habian proyectado sobre su nacimiento, desechar las vanas e malivolas voces que contra ella se han prorrumpido e divulgado. En este momento del tenor documental, toma la voz de la parte actora la reina Dña. Juana, y en presencia del Rey, del Príncipe Carlos, de los embajadores de Francia, de los nobles españoles, de los prelados y caballeros del Consejo Real, jura por Dios, por su madre, sobre los Santos Evangelios, tocando corporalmente la Señal de la Cruz, que ella está cierta, que la dicha Princesa doña Juana es hija legitima e natural del dicho Sennor Rey e mia; después de lo cual, ambos reyes dan por válido el juramento primero, anulan el segundo, declarando que nunca habrán ni tendrán a la Infanta Isabel por Princesa e por heredera de sus reinos, ordenando a los nobles y dignatarios de la Corte, y a los procuradores de las ciudades, que ratifiquen aquel juramento y tengan e intitulen como princesa y heredera a doña Juana. Ordenan, en fin, que se den cartas y provisiones en este sentido, y en las fórmulas finales mandan dar esta escritura $y$ otras tales, firmadas de sus nombres, selladas con sus sellos y testimoniadas por los notarios reales.

Se cierra el documento con la fecha en Valdelozoya de Santiago a 26 de octubre de 1470 .

Las firmas autográficas de ambos reyes (Yo el Rey, Yo la Reyna) van al pie y bajo cada una de ellas, los sellos de placa de ambos soberanos. Es el del Rey el ordinario de Castilla, de placa, sobre cera roja ostentando el escudo cuartelado de castillos y leones, timbrado de corona real y flanqueado por sendas ramas de roble. En torno, filacteria con la leyenda:

S: DOMINI: HENRICI: DEI: GRACIA: REGIS: CASTELLE: ET: LEGIONIS.

El de la reina es partido: $10^{\circ}$ cuartelado de castillos y leones, $2 .^{\circ}$ las quinas de Portugal sobre cruz florenzada y pordura de ocho castillos.

Filacteria en torno con la leyenda:

SIGILLUM: IOANNE: DEY: GRACIA: REGINA: CASTELLE: ET: LEGIONIS.

De este documento, conservado actualmente en el Instituto de Valencia de Don Juan, se hicieron varios originales, como nos lo dice el texto, y como ocurre siempre en originales múltiples, aunque substan- 
cialmente fueran unánimes, debían diferir en lo accidental, pues las copias que de ellos se hicieron en siglos posteriores, contienen variantes que acusan bien claramente diversidad de procedencia.

Deriva directamente del ejemplar que hemos descrito, la copia que lo acompaña en el mismo Instituto de Valencia de Don Juan, literal, aunque con algunas alteraciones ortográficas y, generalmente, respetando la grafía del original. Está extraída en el siglo XVI en letra bastarda amplia, clara e inclinada, con correcta separación de palabras y regular espaciación de las líneas.

Otra copia existe en el Archivo de Simancas, que se publicó en las Memorias de Don Enrique IV de Castilla, que contiene la Colección diplomática del mismo Rey. Esta publicación, ordenada por la Real Academia de la Historia, comenzó a imprimirse en junio de 1835 y estaba ya suspendida en 1837, reanudándose su edición en 1913, año en el que aparece el Tomo II, en el que está incluida (pág. 619) la copia de Simancas a la que nos referimos, con la anotación imprecisa de "Copia antigua en el Archivo de Simancas». Como tal copia es históricamente irreprochable; pero modifica totalmente la ortografía y en ella se aprecian algunas variantes (lo que nos da la convicción de que se extrajo de un original distinto del que aquí estudiamos) y además el autor de la copia (no el de la edición) no consiguió leer la fecha de lugar ni el día del documento.

\section{TRANSCRIPCION}

Conoçida cosa sea a todos quantos ${ }^{1}$ la presente escriptura vieren, commo yo don Enrique, por la graçia de Dios Rey de Castilla, de León, de Toledo, de Galisia, de Seuilla, de Cordoua, de Murçia, de Jahén, del Algarbe, de Agesira, de Gibrartar e Sennor de Viscaya e de Molina. E yo la Reyna donna Juana, muger del dicho Rey mi sennor. Por quanto segund derecho diuino e vmano e las leyes de aquestos Reynos, la herençia e subçesión e el prençipado dellos es deuido e pertenesce a la prinçesa donna Juana nuestra muy cara e muy amada fija legitima e natural; la qual estando en estos dichos Reynos en toda pas e sosiego e tranquelidad, de consentimiento e actoridad de mí el dicho Sennor Rey, fue $^{2}$ pública e solepnement intitulada, jurada ${ }^{3}$ e nobrada e llamada $e$ reçebida e auida e tenida por Prinçesa $e^{4}$ primogenita heredera e subçesora destos dichos mis Reynos e Sennoríos para despues de mis días; asy por mí el dicho Sennor Rey commo por los perlados e grandes destos dichos Reynos, e por los procuradores de las çibdades e villas dellos. E commo quier que despues al tiempo que la Ynfante donne 
Ysabel, hermana de mí el dicho Sennor Rey se reduxo a mi seruiçio e obediençia por atajar algunas guerras e males ${ }^{5}$ e diuisiones que en estos dichos Reynos por entonçes avían e se esperauan; e porque la dicha Ynfante prometió e juró publica e solepnemente de estar sienpre muy conforme conmigo e en mi corte ${ }^{6}$ e me obedeçer acatar e seruir e seguir commo a su Rey e Sennor e padre, e dexarse e apartarse de todos otros caminos e cosas de que yo pudiese reçebir deseruiçio e enojo; e por mi mano reçebir ${ }^{8}$ toda merçed commo de su sennor e padre, e no por otras vias algunas; e de casar e que casaría con quien yo acordase e determinase de acuerdo e consejo de çiertos perlados e caualleros que comigo estauan, e non con otra persona alguna. $E$ asy mesmo porque me prometió e juró de trabajar e procurar con todas sus fuerças e poder que todas las çibdades e villas e lugares destos dichos mis Reynos fuesen redusidas ${ }^{9}$ a mi obediençia; e que para ello darían todas las cartas e prouisiones que fuesen menester. $E^{10}$ yo el dicho Sennor Rey, creyendo que ella guardaría e cumpliría las cosas suso dichas de que se esperaua seguir grand concordia e pas e sosiego e traquilidad en estos dichos mis Reynos, e la Corona Real dellos ser restaurada e reparada, consentí e mandé que la dicha Ynfante, mi hermana, fuese, segund que fue yntitulada e jurada por Prinçesa e heredera destos dichos Reynos" asy por mí commo por algunos perlados e grandes e procuradores e çibdades e villas dellos. Pero la dicha Ynfante, mi hermna, non guardó nin cumplió las cosas suso dichas que asy me prometió e juró. Antes, en grand deseruiçio ${ }^{12}$ e danno e menospreçio mío, e en quebrantamiento de la dicha su fee e juramento, e contra la dispusiçión de las leys destos dichos Reynos e en gran turbaçión e escandalo dellos, fiso e cometió todo to contrario, e touo en ello muchas maneras e formas de malo y detestable enxemplo, en grand menospreçio mio e contra mi preheminençia Real e en derogaçión della, segund que todo es público o notorio en estos dichos mis Reynos ${ }^{13}$. Por lo qual e porquel dicho juramento a ella fecho fue en danno e perjuysio de la dicha Prinçesa donna Juana mi fija, e de su derecho e contra el primero juramento a ella fecho ${ }^{14}$, el dicho segundo juramento e omenaje fechos a la dicha mi hermana non valieron nin pueden nin deuen ser guardados nin complidos nin conseguir efecto. $E^{14}$ por la presente escriptura, yo el dicho sennor Rey, de mi propio motu e çierta çiençia e poderío real absoluto e commo mejor puedo, asy lo pronuncio e declaro; e a mayor ${ }^{16}$ abondamiento $\operatorname{los}^{17}$ reuoco caso e anulo, e do por ningunos ${ }^{18}$ e de ningund valor e efecto, e quiero e mando que nos sean complidos nin guardados por los dichos perlados e grandes e caualleros, nin por las çibdades e villas de mis Reynos, nin por los procuradores dellas nin por alguno dellos ${ }^{19}$ nin por otras algunas per- 
sonas mis subditos e naturales, a los quales e a cada vno dellos e a sus linajes e personas e bienes yo do por libres e quitos para siempre jamás. Por ende yo la dicha Sennora Reyna ${ }^{20}$ por mayor conseruación del derecho de la dicha Prinçesa donna Juana, mi fija, e de su onor e fama, e por más clarificar la verdad e confundir e desechar ${ }^{21}$ las vanas e maliuolas ${ }^{22}$ boses que contra ella se han prorrumpido e diuulgado, en presençia del dicho Rey mi Sennor e del reuerendisimo in Christo Padre el Cardenal de Albi, mi muy caro e muy amado amigo, e de los otros embaxadores e procuradores del muy alto e muy poderoso Prinçipe el Rey de Françia, mi muy caro e muy amado primo, e del muy ylustre Prinçipe el Duque de Guiana, su hermano, e de los perlados e grandes e caualleros e otras personas del consejo del dicho Rey mi sennor, e de algunos procuradores de las cibdades e villa destos Reynos, e de todos los otros de la corte del dicho Rey mi sennor que presentes están, fago juramento a Dios e Santa María e a la Sennal de la Crus $\downarrow$ que con mi mano derecha corporalmente toqué, en las manos del dicho Cardenal, e a las palabras de los Santos Euangelios do quier que están escriptos, que yo se çierto ${ }^{23}$ que la dicha Prinçesa donna Juana e fija legítima e natural del dicho Rey mi sennor e mía, e que por tal la reputé e traté e toue sienpre, e la tengo e reputo agora. E otrosy yo el dicho Sennor Rey de Castilla e de León juro en la forma suso dicha que yo creo e tengo verdaderamente que la dicha Prinçesa donna Juana es mi fija legítima e natural e de la dicha Reyna mi muger, e que sienpre la toue e traté e reputé por mi fija legítima e que por tal la tengo e reputo agora e la entiendo de aquí adelante para sienpre por tal ${ }^{24}$ aver e tener e reputar e tratar. E demás desto yo el dicho Sennor Rey e yo la dicha Reyna, su muger, por la presente escriptura aprouamos, loamos e ratificamos el primero juramento por nos fechos a la dicha Prinçesa donna Juana, nuestra fija, commo a Prinçesa e primogénita heredera destos dichos Reynos e Sennoríos, e a mayor abondamiento agora de nueuo la reçebimos e yntitulamos por Prinçesa e primogénita heredera e subçesora de mi el dicho Sennor Rey e destos dichos mis Reynos e Sennoríos para después de mis días, e juramos en la forma suso dicha de la sienpre por tal aver e tener e guardar e tratar $^{25}$. E que de aquí adelante nunca más yntitularemos nin llamaremos nin avremos nin ternemos a la dicha Ynfante donna Ysabel por Prinçesa 'ni heredera ni subçesora destos dichos Reynos nin sennoríos en manera alguna. E otrosy yo el dicho Sennor Rey por esta escriptura mando a don Juan Pacheco, Maestre de Santiago, e don Alonso de Fonseca, Arçobispo de Seuilla, e don Aluaro de Stunniga, Duque de Areualo, e don Diego Furtado de Mendoça, Marqués de Santillana, e don Rodrigo Alonso Pimentel, Conde de Benauente, e don Pedro Gonça- 
les de Mendoça, Obispo de Sigüença, e don Juan de Acunna, Duque de Valençia, e don Diego de Çunniga, Conde de Miranda, e don Ynnigo Lopes de Mendoça, Conde de Tendilla, e Andrés de Cabrera, mi Mayordomo, e Ferrando de Pareja, Adelantado Mayor del Reyno de Gallizia, e al doctor Pedro Gonçales de Avila, el al Liçençiado Antón Nunnez de Çibdad Rodrigo, mi Contador Mayor e del mi Consejo, e al doctor Garçía Lopes de Madrid, del mi Consejo. E a cada vno de vos, e a todos los otros caualleros e personas del mi Consejo ${ }^{26}$, e a los procuradores de las çibdades e villas de mis Reynos que al presente comigo estades, que luego asy mesmo aprouedes ${ }^{27}$ e retifiquedes el dicho primero juramento fecho a la dicha Prinçesa, mi fija, e lo fagades ${ }^{28}$ de nueuo, e de aquí adelante la reçibades e yntituledes ${ }^{29}$ e llamedes e guardedes e ayades e tengades por Prinçesa e primogénita heredera $e^{30}$ subçesora mía e destos dichos mis reynos e sennoríos para despues de mis días. $E$ que de agora para entonçes la reçibades e obedescades por Reyna e Sennora dellos; e de aquí adelante non yntituledes nin nombredes nin llamades $^{31}$ nin ayades nin tengades a la dicha Ynfanta donna Ysabel por Prinçesa nin heredera nin subçesora destos dichos mis Reynos e Sennoríos, en manera alguna como dicho es. E fagades sobre todo ello a la dicha Prinçesa, mi fija, todos los juramentos e omenajes e seguridades e solempnidades que en tal caso se requieren ${ }^{32}$. $E$ otrosy mando a todos los otros perlados $\mathrm{e}^{33}$ grandes e caualleros destos mis Reynos que son absentes, e a las çibdades e villas dellos e a sus procuradores en su nombre, e a cada vno dellos que asy mesmo lo aprueuen e retifiquen ${ }^{34}$ e juren e guarden e cumplan asy, segund que de suso en esta dicha escriptura se contiene. Para lo qual mando dar mis cartas e prouisiones so grandes penas en deuida forma. Por firmesa de lo qual todo, Yo el dicho Sennor Rey e yo la dicha Reyna ${ }^{35}$ su muger, mandamos dar a dimos esta escriptura e otras tales firmadas de nuestros nombres e selladas con nuestros sellos, e las otorgamos ante los secretarios e notarios de yuso escriptos, a los quales mandamos e rogamos que las signasen con sus signos; que fueron dadas e otorgadas en el Val de Loçoya en Santiago ${ }^{36}$ a veynte e seys dias del mes de Otubre, anno del nasçimiento de nuestro Sennor Ihesu Christo de mill e quatroçientos e setenta annos.

Yo el Rey.

(Sello de placa del Rey)

Yo la Reyna.

(Sello de placa de la Reyna) 
Nos don Iohan Pacheco, Maestre de la Orden de la Cauallería de Santiago; e don Alfonso de Fonseca, Arçobispo de Seuilla; e don Aluaro de Stunniga, Duque de Areualo e Conde de Plasençia; e don Diego Furtado de Mendoça, Marqués de Santillana Conde del Real; e don Pero Gonçales de Mendoça, Obispo de Sigüença; e don Iohan de Acunna, Duque de Valençia; e don Diego de Stunniga, Conde de Miranda; e don Ynnigo Lopes de Mendoça, Conde de Tendilla; e el doctor Pero Gonçales de Avila, del Consejo del Rey nuestro Sennor; e los otros perlados e caualleros e personas que de yuso en esta escriptura firmamos nuestros nombres, e cada vno de nos: Visto lo suso dicho en esta escriptura contenido, afirmado e jurado e ratificado e aprouado por los dichos sennores Rey e Reyna, e por cada vno dellos, e conseguiendo aquello y el mandamiento a nos sobrello fecho por el dicho Sennor Rey, por esta dicha escriptura de nuestra propia e libre e deliberada voluntad, aprouamos e retificamos el primero juramento, por nos e por cada vno de nos fecho a la dicha sennora Prinçesa donna Juana, fija del dicho Sennor Rey, commo a prinçesa e primogenita heredera destos dichos Reynos e Sennoríos. E a mayor abondamiento agora de nuevo la reçebimos e avemos e tenemos por Prinçesa e primogénita heredera e subçesora del dicho Sennor Rey e destos sus Reynos e Sennorios, para despues de los días del dicho Sennor Rey. E de agora para entonçes la tomamos e reçebimos e obedesçemos por Reyna e Sennora dellos. E juramos a Dios e a Santa María e a la Sennal de la Crus $\dagger$ que con nuestras manos derechas corporalmente tocamos, e a las palabras de los Santos Euangelios do quier que están escriptos. E fasemos pleito e omenaje vna e dos e tres veses, segund fuero e costumbre de España, en manos del dicho Conde de Tendilla, cauallero e ome fijo dalgo, que de nosotros e de cada vno de nos lo reçibe, que de aquí adelante sienpre la yntitularemos e guardaremos e avremos e ternemos por Prinçesa e primogénita heredera e subçesora destos dichos reynos e por Reyna e Sennora dellos, para despues de los días del dicho Sennor Rey, commo de suso dicho es; e le faremos toda reuerençia, e acatamiento; e le guardaremos e faremos guardar todas las otras onrras e preminençias e perrogatiuas que a los prínçipes primogenitos de Castilla e de León son deuidas e se acostumbraron sienpre faser e guardar e las leyes destos Reynos lo disponen e quieren e mandan. E otrosy que de aquí adelante non yntitularemos nin nombraremos nin llamaremos nin ternemos a la dicha Ynfante donna Ysabel por Prinçesa nin heredera nin subçesora destos dichos Reynos ni Sennoríos en manera alguna, e que asy guardaremos e ternemos bien e leal e verdaderamente syn arte e syn enganno, e syn fraude nin cavtela nin fiçión nin simulaçión alguna que non yremos nin vernemos nin pasa- 
remos contra ello nin contra cosa alguna nin parte dello, pública nin ocultamente, directe nin yndirecte, por ninguna cosa ni color que sea e ser pueda, agora nin de aquí adelante en ningund tiempo nin por alguna manera so pena que sy lo que Dios no quiera lo contrario fisiéremos, que aquel o aquellos de nos que lo quebrantare, por el mismo fecho sea perjuro e caya e yncurra en las penas e casos puestas en derecho contra los quebrantadores de juramento e pleito e omenaje fecho de su libre voluntad y en los otros casos puestos por las leyes destos Reynos contra los que deseredan a sus reyes e Prínçipes. E otrosy seguramos e prometemos e juramos en la forma suso dicha que non pederemos absoluçión nin relaxaçión, nin comutaçión deste dicho juramento e pleito omenaje a nuestro muy santo padre nin a otro alguno que poder e abtoridad tenga para lo conçeder; e puesto que nos sea dado e otorgado motu propio, o en otra qualquier manera, non vsaremos nin nos aprouecharemos dello; por firmesa e seguridad de lo cual, firmamos esta presente escriptura e otras tales de nuestros nombres, e las fesimos sellar con los sellos de nuestras armas, e las otorgamos ante los secretarios e notarios de yuso escriptos a los quales rogamos que las signasen con sus signos. E otrosy, yo Ynnigo Días de Arçeo, procurador de la çibdad de Burgos, cabeça de Castilla, e el liçençiado de Çibdad Rodrigo, procurador de la çibdad de Salamanca, e Aluaro de Bracamonte, procurador de la çibdad de Avila, e don Juan de Mendoça, procurador de la çibdad de Guadalajara, e el doctor Garçía Lópes de Madrid, procurador de la muy noble villa de Valladolid, e Rodrigo de Morales, procurador de la çibdad de Soria. E cada vno de nos en nombre de las dichas çibdades e villas e de cada vna dellas, e commo mejor podamos, otorgamos e conosçemos por la presente escriptura, que retificamos e aprouamos el dicho primero juramento fecho a la dicha Sennora Prinçesa donna Juana, fija del dicho Sennor Rey e de nueuo la juramos en la forma susodicha, segund e por la forma e manera que de suso por los dichos sennores e perlados e grandes e caualleros está jurado e prometido, e en esta dicha escriptura se contiene. E asy mesmo otorgamos dello ante los dichos secretarios las dichas escripturas de vn tenor. Que fueron fechas e otorgadas asy por los dichos perlados e grandes e caualleros, como por los procuradores en la forma suso dicha en el dicho Val de Loçoya, el logar de Santiago, día e mes e anno suso dicho.

Nos el Maestre A. Ispalensis
El Marqués y Conde
El Conde de Benauente $\quad$ El Duque

Saguntinus 

El Conde de Tendilla
El Duque Conde de
El Conde don Diego
Pero Gonçales, doctor

(Calderón) Testigos que fueron presentes a todo lo que dicho es para ello llamados e rogados: Iohan de Ouiedo, Secretario del Rey nuestro Sennor, e Françisco de Tordesiellas, su camarero, e don lohan de Salsedo, su capellán e otros.

(Signo) Yo lohan Ruys del Castillo, notario publico por la avtoridad apostólica e real, e secretario del dicho sennor Rey, fuí presente en vno con los dichos testigos a todo lo suso dicho en esta escriptura contenido e vi prometer e jurar e otorgar así al dicho Sennor Rey e a la dicha Sennora Reyna, commo a los dichos perlados e caualleros que en ella firmaron sus nombres e a los procuradores de las çibdades e villas que de suso van nombrados, e a cada vno dellos esta dicha escriptura e todo lo en ella contenido, la qual va escripta en tres fojas de papel entero, con esta que va mi signo. E por mandado del dicho Sennor Rey e de ruego e otrogamiento de la dicha Sennora Reyna e de los dichos perlados e caualleros e procuradores, puse aquí este mi signo e 10 firmé de mi nombre.

(Rubricado) lohan Ruis

\section{VARIANTES QUE EXISTEN CON LA COPIA DEL ARCHIVO DE SIMANCAS, PUBLICADA EN LA COLECCION DIPLOMATICA}

1... a todos los que

2... Sup. fué

3... jurada e intitulada

4... Sup. E

5... Sup. e males

6... Sup. e en mi corte

7... Sup. e seguir

8... rescibió

9... restituidos

10... Sup. E

11... dichos mis

12... que así me prometió e juró antes, en grande deserviçio

13... Sup. segund que todo es público e notorio en estos dichos mis regnos. 
14... Sup. e contra el primero juramento a ella fechó e

$15 \ldots$ Sup. e

16 ... e por mayor

$17 \ldots$ los

18... ningunos

19... e villas dellos nin por alguno dellos

20... personas e bienes para siempre jamás... (Sic. en la edición) e quanto al dicho primero juramento a ella fecho, perviviendo yo la dicha señora Reina.

21... confundir e tapar e desechar

22... malinas

23... que yo so cierta

24... e por tal

25... agora de nuevo juramos en la forma suso dicha e la rescebimos e intitulamos por Princesa primogénita heredera e subcesora de mi el dicho señor Rey e de dichos mis regnos despues de mis días de la siempre por tal aver e tener e guardar e tratar

26... Sup. la enumeración de todos los caballeros y dignidades, enlazando: e a los procuradores de las çibdades e villas. Es decir, desde la línea $45 \mathrm{de} / \mathrm{f}^{\circ} \mathrm{Iv}$., hasta la línea $8 \mathrm{de} / \mathrm{f}^{\circ} 2 \mathrm{v}$.

27... Sup. aprouedes

28... fagais

$29 . .$. rescibades la intitulación

30... Sup. e

$31 \ldots$ llamades

32... Sup. desde $E$ fagades... (Linea $18, f .^{\circ} 2$ r.) hasta... que en tal caso se requieren (línea $21, f^{\circ} 2 \mathrm{r}$.), enlazando: otrosi mando a todos los otros

33... Sup. perlados $\mathrm{e}$

$34 \ldots$ ratifiquen

35... señora Reina

36... En blanco la fecha tópica. 


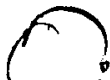

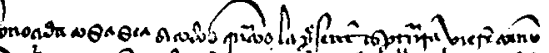

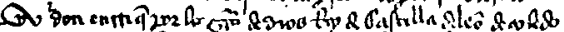

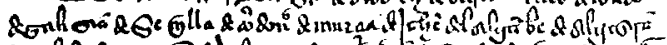
Subpas Q

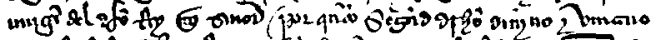

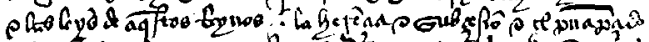

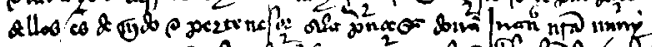

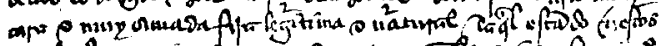

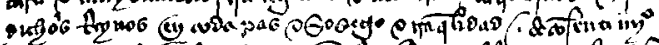

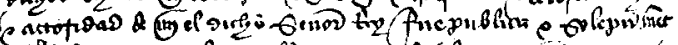

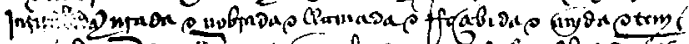

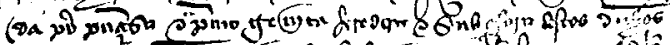

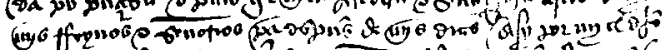

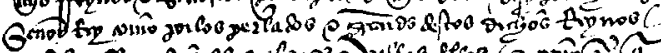

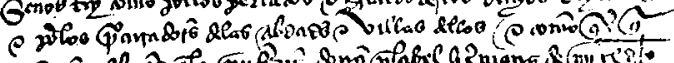

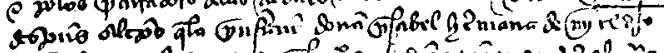

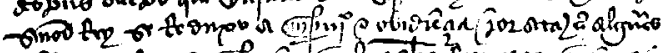

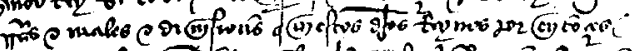

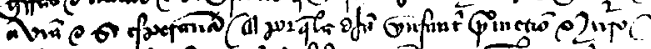

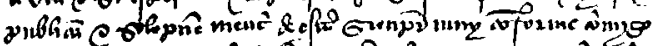

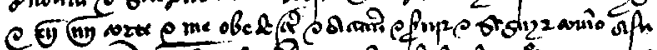

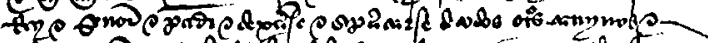

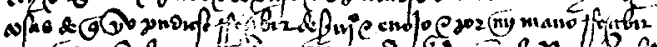

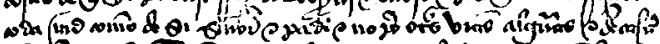

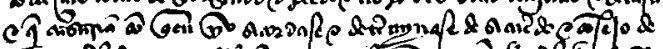

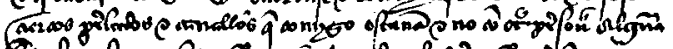

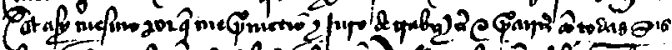
fini

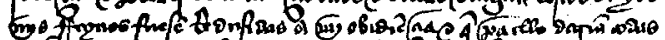

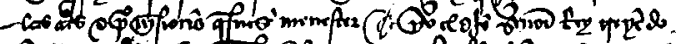

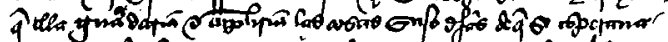

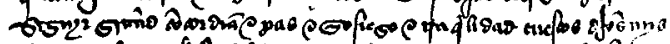

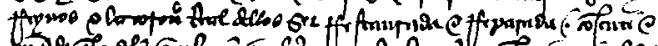

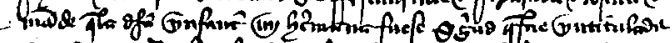

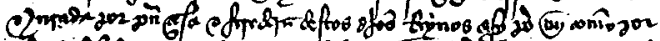

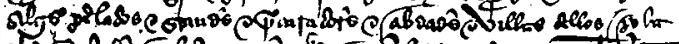

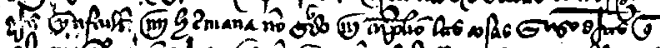

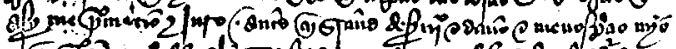

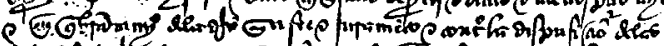

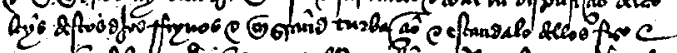

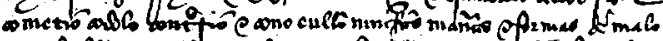

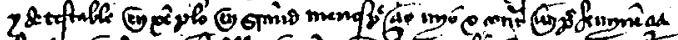

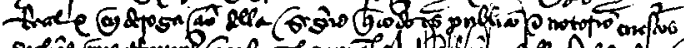

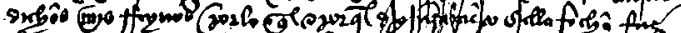

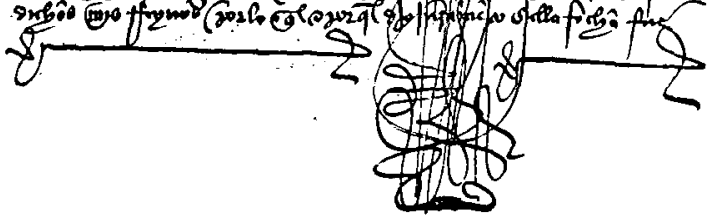




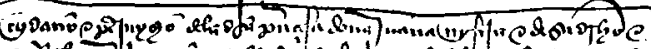

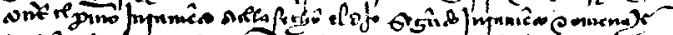

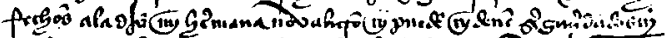

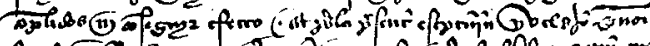

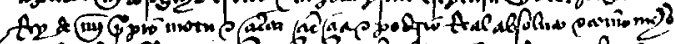

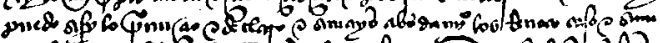
co 8 s

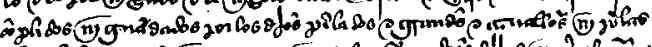

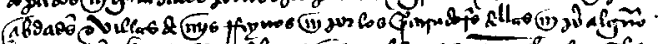

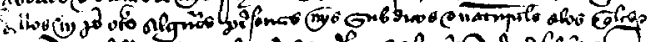

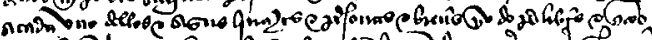

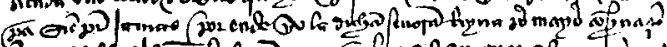

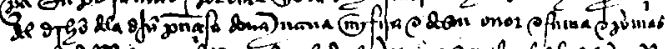

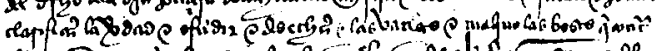

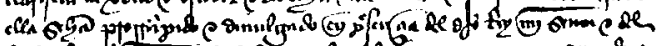

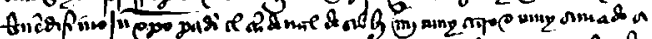

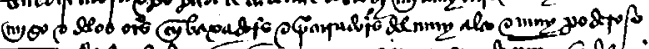

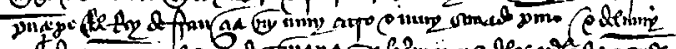

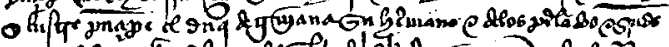

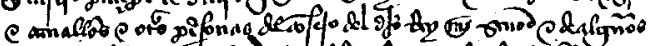

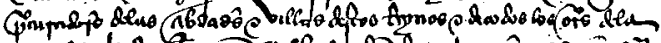

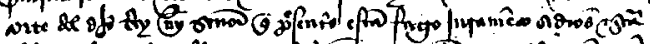

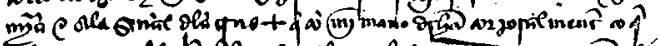

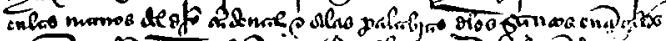

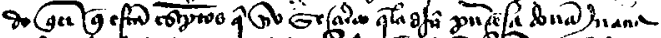

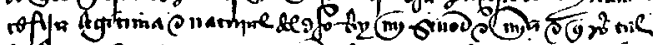

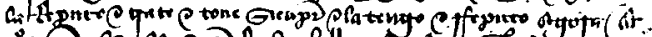

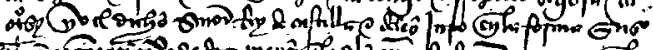

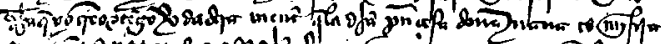

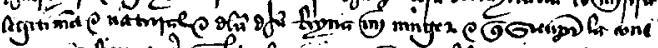

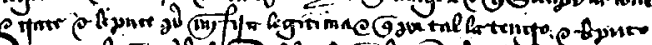

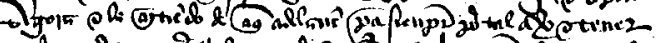

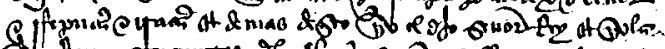

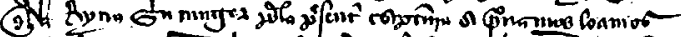

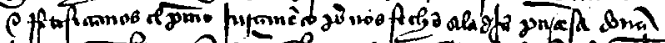

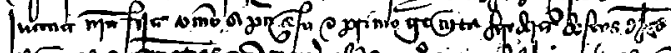

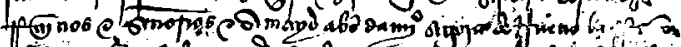

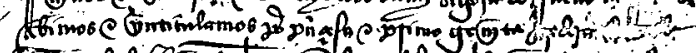
Aoting

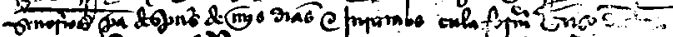

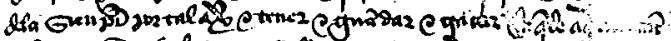

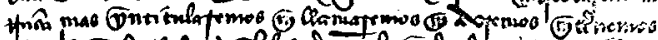

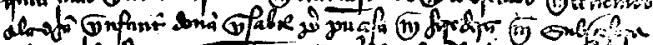

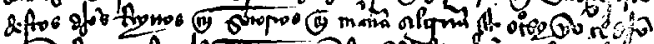

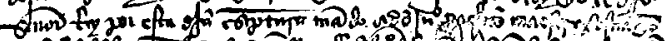

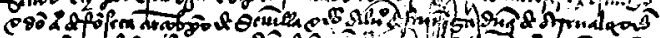

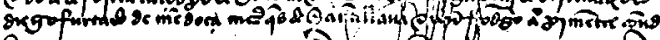

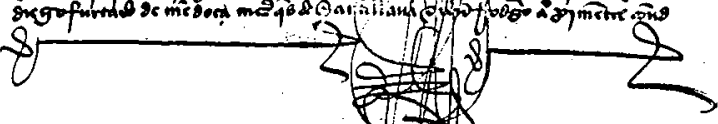




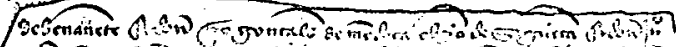

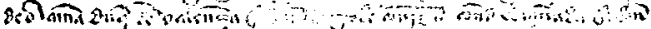

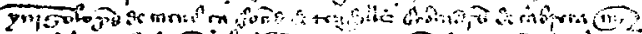

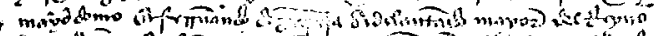

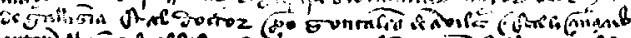

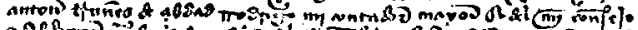

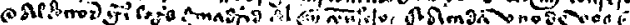

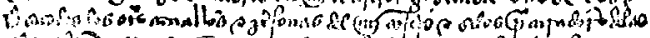

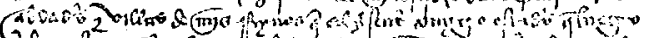

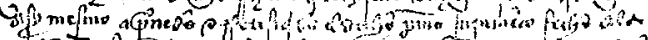

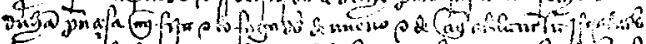

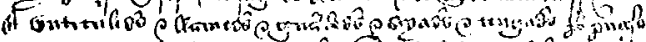
CभT"

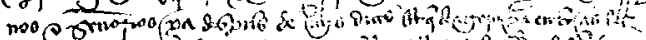

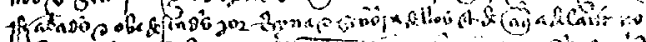

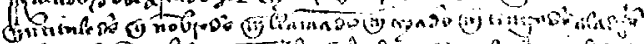

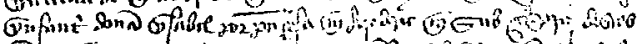

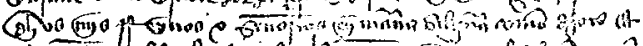

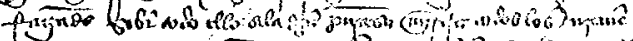

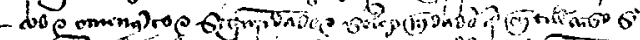

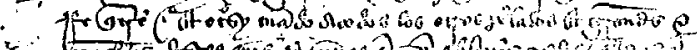

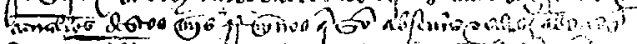

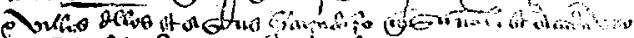

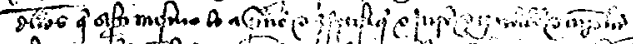

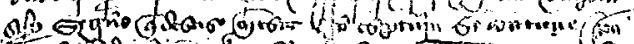

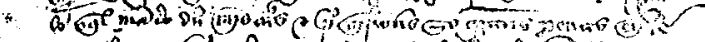

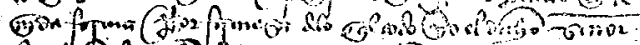

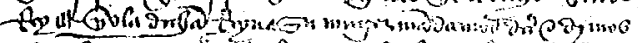

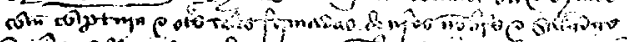

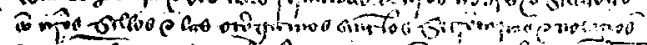

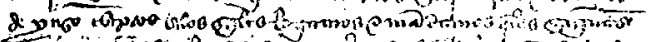

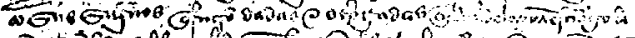

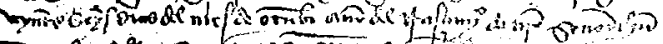

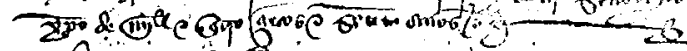

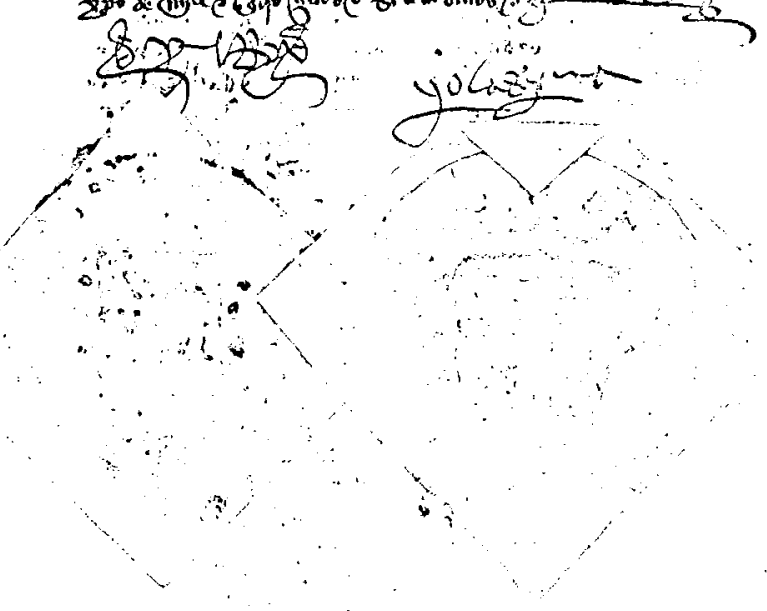



Ion oup on \& fonda or

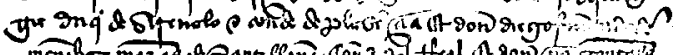

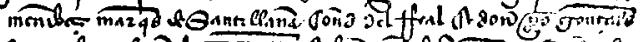

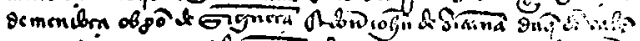

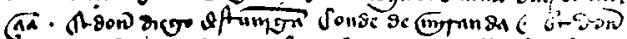

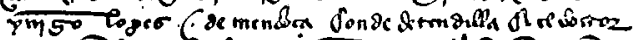

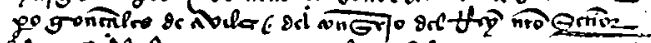

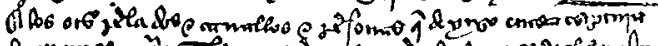
fिम

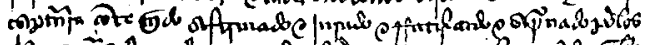

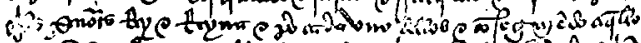

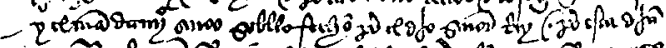

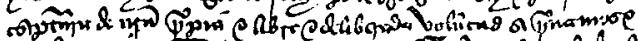

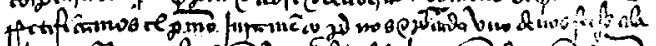

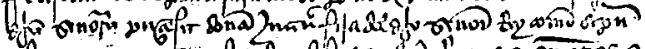

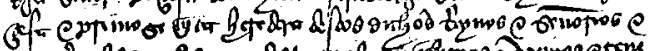

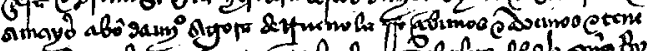

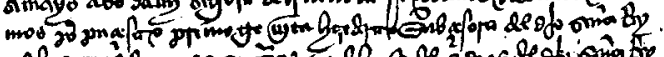

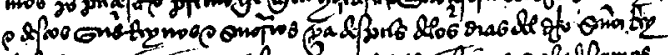

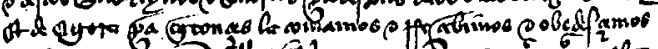

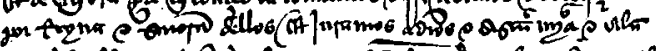

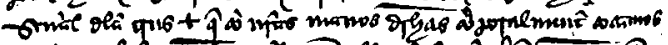

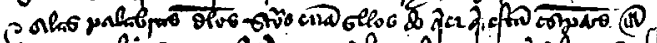

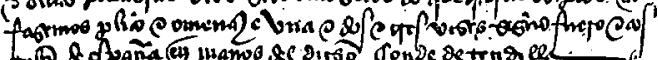
40 R of

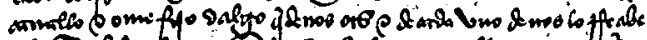

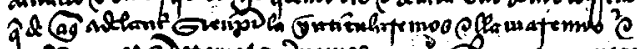

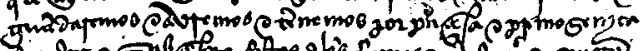

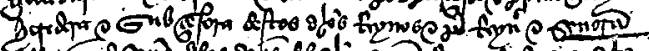

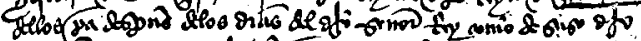

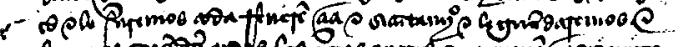

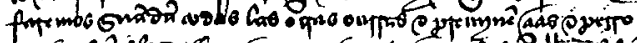

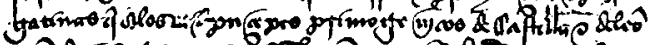

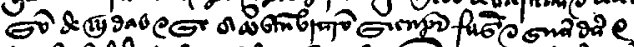

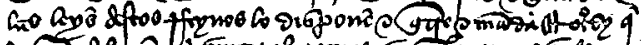

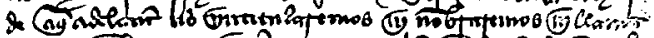

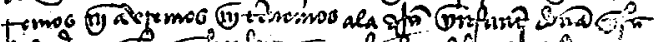

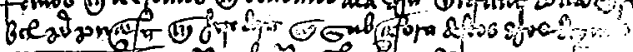

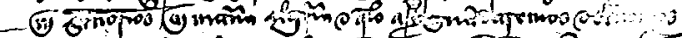

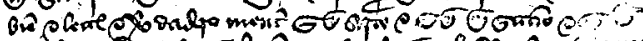

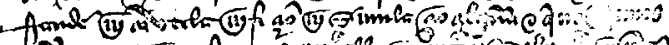

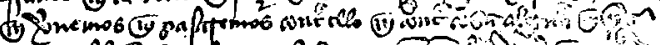

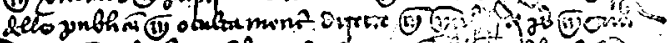

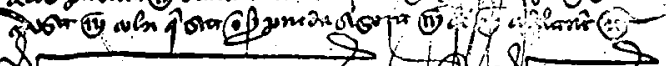

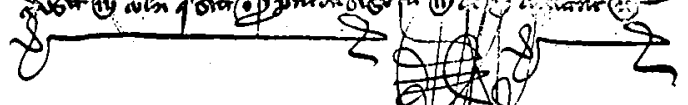









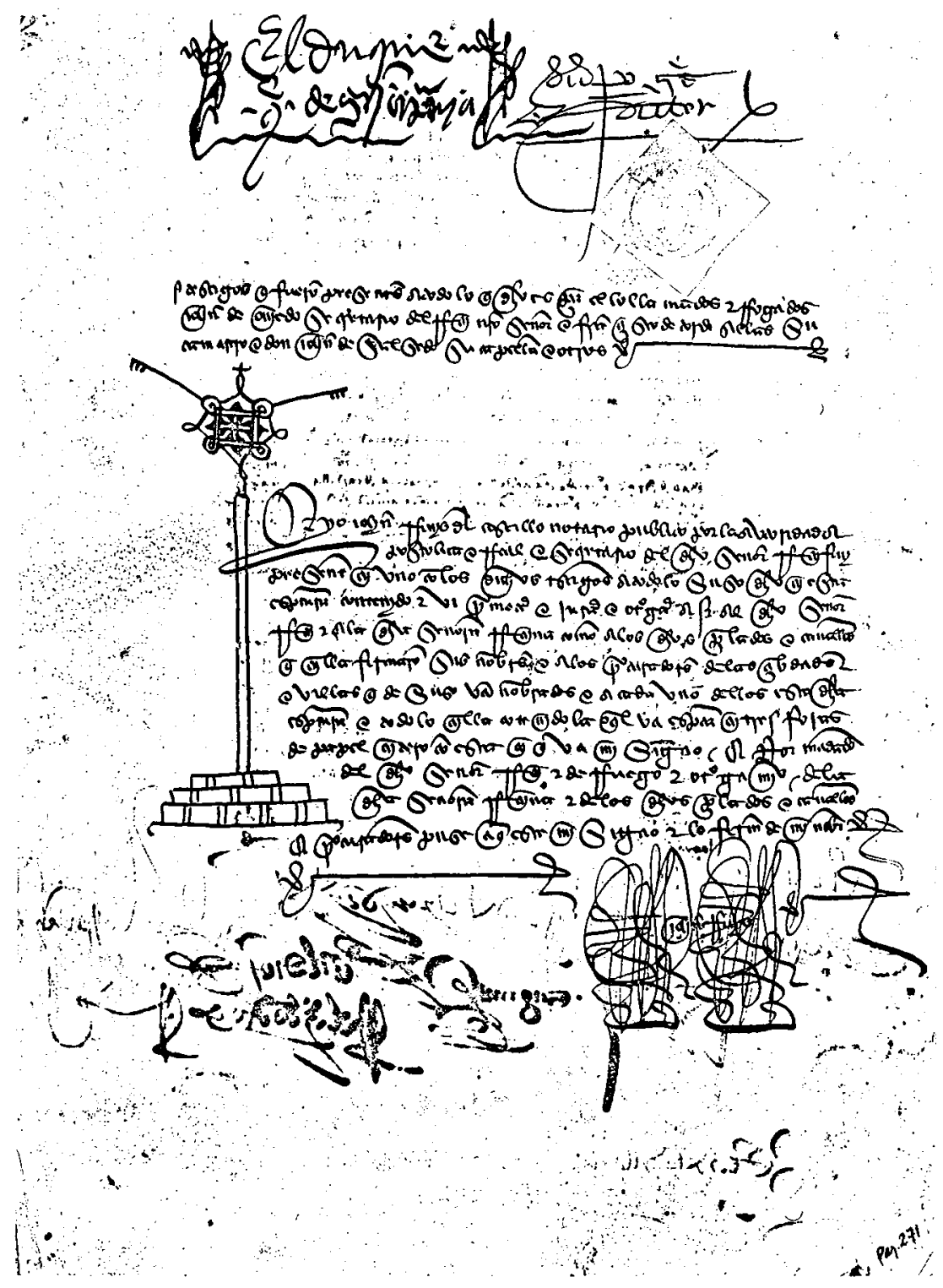

